\title{
Pseudoathletic Appearance: A Case Report in a Male
}

\author{
Joana Moreira1, Gonçalo Gomes Pereira², Mário Santos', Vaz de Macedo² \\ ${ }^{1}$ General Practice Department, USF Covelo, Porto, Portugal \\ ${ }^{2}$ General Practice Department, USF Sem Fronteiras, Santa Maria da Feira, Portugal \\ Email: joanamoreira95@gmail.com
}

Received 22 October 2015; accepted 1 December 2015; published 4 December 2015

Copyright (C) 2015 by authors and Scientific Research Publishing Inc.

This work is licensed under the Creative Commons Attribution International License (CC BY). http://creativecommons.org/licenses/by/4.0/

(c) (i) Open Access

\begin{abstract}
Multiple Symmetric Lipomatosis (MSL) is a rare condition characterized by a symmetrical pattern of massive fatty deposits. This condition predominates in males, between 30 and 60 years. In this article, the authors present a case report of a 47-year-old man that resorted to consultation to perform routine medical exams, without any complaint associated. Physical examination shows multiple bilateral swellings in the proximal region of the upper limbs and analytically presents hyperuricemia, hypertriglyceridemia, hypercholesterolemia and changes in hepatic tests. CT revealed the presence of non-encapsulated homogeneous masses of adipose tissue in the proximal region of the limbs. Currently the patient is asymptomatic, being monitoring in consultation.
\end{abstract}

\section{Keywords}

Symmetric Multiple Lipomatosis, Hyperuricemia, Hypertriglyceridemia, Hypercholesterolemia

\section{Introduction}

Madelung Disease (MD), also called Multiple Symmetric Lipomatosis (MSL), is a rare disease characterized by the growth of non-encapsulated and painless lipomas, preferably located in the neck, scapular region, the proximal part of the upper and limbs, excluding the face and distal part of the limbs [1]. It is more common in Mediterranean countries and predominantly affects males (15:1) [2], between 30 and 60 years [3]. Its pathogenesis is still unknown and may be associated with neuropathy, hyperuricemia, liver disease and malignant tumors of the airways and digestive tract [4]. Two types of Madelung's disease have been described [5]. In type 1, most common in men, fat accumulates around the neck, submental region, and upper back, known as "Madelung collar" [4]. In type 2, typical in women, lipomas are distributed over much of the body, including shoulders, upper arms, the hips and thighs, giving a pseudoathletic appearance [4]. Fatty deposits rarely extend to the mediastinum and 
larynx in type 2 [6]. Most patients have a history of chronic alcoholism [5].

\section{Case Report}

A male patient, 47 years old, Caucasian, resorted to consultation to require routine analytical study. He had no complaints. Physical examination showed a multiple bilateral swellings in the proximal region of the upper limbs, without neck involvement (Figure 1(a), Figure 1(b)). Analytical studies were carried out, showing hyperuricemia, hypertriglyceridemia, hypercholesterolemia (at the expense of HDL-c), macrocytosis and changes in hepatic tests (Table 1). The abdominal ultrasound demonstrated hepatomegaly and steatosis. He denied abuse of alcohol, referring only sporadic consumption. The patient was referred to the hospital of reference, where he underwent a biopsy and a CT. Biopsy of the mass revealed adipose tissue with interstitial fibrosis. CT revealed the presence of non-encapsulated homogeneous masses of adipose tissue in the proximal region of the upper limbs, without mediastinal involvement. It was proposed a surgical excision, the patient refuses, because he remained asymptomatic. Currently the patient remains under analytical and imaging follow-up, and started treatment with statin and uricosuric.

\section{Conclusion}

The diagnosis of MSL is primarily based on physical examination, clinical history, and imaging studies [5]. With this case report, the authors intend to demonstrate that although many authors advocate a phenotypic exclusive subtype 2 of the disease, for women, this is not always the case. The mechanism, where there is fat deposition in different parts of the body, is not completely understood, so it is important to continue research in this area. Due to the morphological characteristics of the subtype 2, which can give a pseudoathletic aspect, it may lead to a subdiagnosis of the disease in male. Lipid disorders, liver disease, and hypothyroidism are frequent comorbidities, as well, neuropathy, including sensory, motor, and autonomic polyneuropathy, which are observed in about $85 \%$ of patients [7], and the latter is associated with sudden cardiac death [8]. The growth of lipomatous masses can cause dyspnea, dysphagia, and superior vena cava syndrome, depending on the location

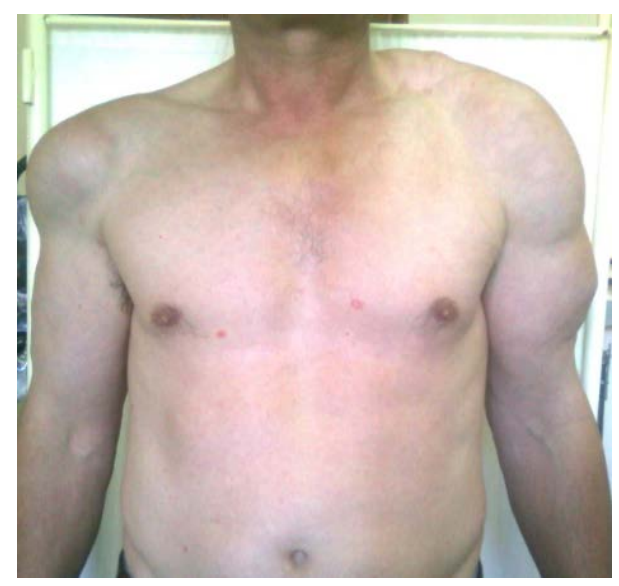

(a)

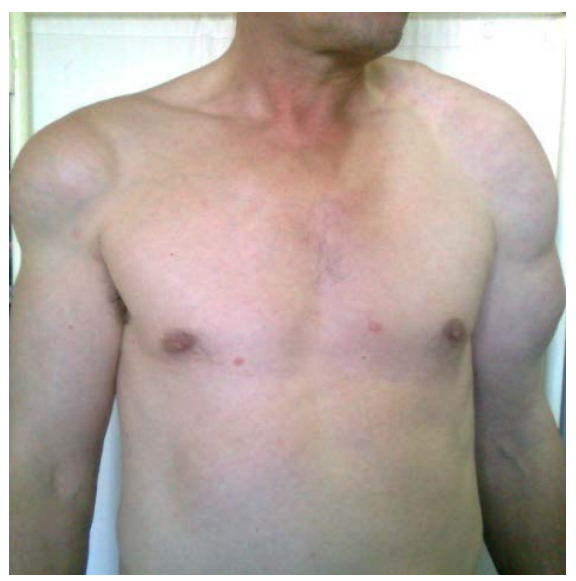

(b)

Figure 1. Male patient with a typical female lipomatous masses distribution.

Table 1. Results of the analytical study and the reference values adopted.

\begin{tabular}{cccccccccc}
\hline Venous Blood & UA & TG & TC & HDLc & Hg & MCV & GOT & GPT & GgT \\
\hline $\begin{array}{c}\text { Conventional } \\
\text { Units }\end{array}$ & $9.3 \mathrm{mg} / \mathrm{dL}$ & $198 \mathrm{mg} / \mathrm{dL}$ & $296 \mathrm{mg} / \mathrm{dL}$ & $102 \mathrm{mg} / \mathrm{dL}$ & $10.9 \mathrm{~g} / \mathrm{dL}$ & $110.1 \mathrm{fL}$ & $72 \mathrm{U} / \mathrm{L}$ & $83 \mathrm{U} / \mathrm{L}$ & $66 \mathrm{U} / \mathrm{L}$ \\
$\begin{array}{c}\text { Reference } \\
\text { Values }\end{array}$ & $\begin{array}{c}2.5-6.2 \\
\mathrm{mg} / \mathrm{dL}\end{array}$ & $\begin{array}{c}<150 \\
\mathrm{mg} / \mathrm{dL}\end{array}$ & $\begin{array}{c}<200 \\
\mathrm{mg} / \mathrm{dL}\end{array}$ & $\begin{array}{c}>60 \\
\mathrm{mg} / \mathrm{dL}\end{array}$ & $\begin{array}{c}11.5-16.5 \\
\mathrm{~g} / \mathrm{dL}\end{array}$ & $\begin{array}{c}76.0-96.0 \\
\mathrm{fL}\end{array}$ & $\begin{array}{c}14-36 \\
\mathrm{U} / \mathrm{L}\end{array}$ & $\begin{array}{c}9-52 \\
\mathrm{U} / \mathrm{L}\end{array}$ & $\begin{array}{c}12-43 \\
\mathrm{U} / \mathrm{L}\end{array}$ \\
\hline
\end{tabular}

UA-Uric Acid; TG—Triglycerides; TC—Total Cholesterol Levels; HDLc_HDL Cholesterol; Hb-Hemoglobin; MCV—Medium Globular Volume; GOT_Glutamic Oxaloacetic Transaminase; GPT—Glutamate Pyruvate Transaminase; GgT_Gamma-glutamyl Transferase. 
of the deposits [8]. The diet has no effect on the growth of lipomas and alcohol withdrawal is, so far, the nonsurgical therapeutic measure which has been proven most effective [9]. The surgical treatments either by lipectomy or by liposuction are the only ones so far proved effective [9]. Despite its generally benign course, there may be a substantially high mortality in individuals with MSL, so it is relevant to monitor these patients.

\section{References}

[1] Rodrigues, G. (2008) Lipomatose Simetrica Múltipla: Síndrome ou Doença? UBI.

[2] Jiménez Aragón, F., et al. (2013) Enfermedad de Madelung. Acta Otorrinolaringológica Española, 64, 166-167. http://dx.doi.org/10.1016/j.otorri.2011.10.003

[3] Sokolov, M., Mendes, D. and Ophir, D. (2010) Madelung's Disease. IMAJ, 12, 253-254.

[4] Busetto, L., et al. (2003) Differential Clinical Expression of Multiple Symmetric Lipomatosis in Men and Women. International Journal of Obesity, 27, 1419-1422. http://dx.doi.org/10.1038/sj.ijo.0802427

[5] Yeh, N.-C., Yang, C.-Y., Chou, C.-W., Yen, F.-C., Lee, S.-Y. and Tien, K.-J. (2012) Madelung's Disease. Journal of Clinical Endocrinology \& Metabolism, 97, 3012-3013. http://dx.doi.org/10.1210/jc.2012-1649

[6] Lopez-Ceres, A., Aguilar-Lizarralde, Y., Villalobos Sánchez, A., Prieto Sánchez, E. and Valiente Alvarez, A. (2006) Benign Symmetric Lipomatosis of the Tongue in Madelung's Disease. Journal of Cranio-Maxillofacial Surgery, 34, 489-493. http://dx.doi.org/10.1016/j.jcms.2006.06.003

[7] Josephson, G., Sclafani, A. and Stern, J. (1996) Benign Symmetric Lipomatosis (Madelung’s Disease). Otolaryngology-Head and Neck Surgery, 115, 170-171. http://dx.doi.org/10.1016/S0194-5998(96)70159-6

[8] Fonseca, V.R., Freitas, C., Palmeira, M., Ferreira, C. and Victorino, R. (2012) Cardiac Noradrenergic Denervation in a Patient with Multiple Symmetric Lipomatosis. Cardiology, 121, 160-163. http://dx.doi.org/10.1159/000336951

[9] Bancroft, W., et al. (2006) Benign Fatty Tumours: Classification, Clinical Course, Imaging Appearance and Treatment. Skeletal Radiology, 35, 719-733. http://dx.doi.org/10.1007/s00256-006-0189-y 